BNL-79233-2007-CP

\title{
Thermal emittance measurement design for diamond secondary emission
}

\author{
Q. Wu, I. Ben-Zvi, A. Burrill, X. Chang, D. Kayran, \\ T. Rao, J. Smedley
}

Presented at the $22^{\text {nd }}$ Particle Accelerator Conference (PAC)

Albuquerque, New Mexico

June $25-29,2007$

\author{
Collider-Accelerator Department \\ Brookhaven National Laboratory \\ P.O. Box 5000 \\ Upton, NY 11973-5000 \\ www.bnl.gov
}

Notice: This manuscript has been authored by employees of Brookhaven Science Associates, LLC under Contract No. DE-AC02-98CH10886 with the U.S. Department of Energy. The publisher by accepting the manuscript for publication acknowledges that the United States Government retains a non-exclusive, paid-up, irrevocable, world-wide license to publish or reproduce the published form of this manuscript, or allow others to do so, for United States Government purposes.

This preprint is intended for publication in a journal or proceedings. Since changes may be made before publication, it may not be cited or reproduced without the author's permission. 


\section{DISCLAIMER}

This report was prepared as an account of work sponsored by an agency of the United States Government. Neither the United States Government nor any agency thereof, nor any of their employees, nor any of their contractors, subcontractors, or their employees, makes any warranty, express or implied, or assumes any legal liability or responsibility for the accuracy, completeness, or any third party's use or the results of such use of any information, apparatus, product, or process disclosed, or represents that its use would not infringe privately owned rights. Reference herein to any specific commercial product, process, or service by trade name, trademark, manufacturer, or otherwise, does not necessarily constitute or imply its endorsement, recommendation, or favoring by the United States Government or any agency thereof or its contractors or subcontractors. The views and opinions of authors expressed herein do not necessarily state or reflect those of the United States Government or any agency thereof. 


\title{
THERMAL EMITTANCE MEASUREMENT DESIGN FOR DIAMOND SECONDARY EMISSION*
}

\author{
Q. Wü , I. Ben-Zvi, A. Burrill, X. Chang, D. Kayran, T. Rao, J. Smedley, BNL, Upton, NY 11973, \\ U.S.A.
}

\section{Abstract}

Thermal emittance is a very important characteristic of cathodes. A carefully designed method of measuring the thermal emittance of secondary emission from diamond is presented. Comparison of possible schemes is carried out by simulation, and the most accessible and accurate method and values are chosen. Systematic errors can be controlled and maintained at small values, and are carefully evaluated. Aberration and limitations of all equipment are taken into account.

\section{INTRODUCTION}

The ultimate emittance of a laser-photocathode gun is given by the thermal emittance. As laser shaping techniques improve, this limit is becoming more important. The thermal emittance of positive electron affinity photocathodes in terms of the thermal electron energy is a large fraction of an electron volt, depending on the type of photocathode. The diamond amplified photocathode [1][2] provides a high gain [3] and robust performance. In addition, being a negative electron affinity (NEA) cathode, it promises to deliver a very small thermal emittance. Theoretical expectations as well as measurements in the reflection mode point towards a temperature less than $0.1 \mathrm{eV}$. This was never measured in a transmission mode. Therefore the aim of this work is to measure the thermal emittance of hydrogenated NEA diamond.

The thermal energy of the secondary emission beam depends on the characteristic of the diamond sample, the properties of the hydrogenated surface and the electric field in the diamond, and yet it is expected that the thermal energy is not a strong function of the field. The measurement system should have the ability to measure this small emittance.

The design is shown in Figure 1. The beam coming out of the diamond NEA surface is accelerated towards an anode. The anode has a small hole, to collimate an output beam. The output beam is focused on a screen by a solenoid. The main idea of the measurement is to compensate the strong linear defocusing effect at the anode by applying a linear focusing lens and measure the waist spot size downstream. The waist spot size is only a function of the thermal emittance and is less affected by the other components. Therefore we can compare the measurement with simulation. It can also be calibrated with known thermal emittance electron source such as a

\footnotetext{
*Work supported by National Science Foundation, the U.S. Department of Energy, and the Office of Naval Research. "qiows@bnl.gov
}

thermal cathode.

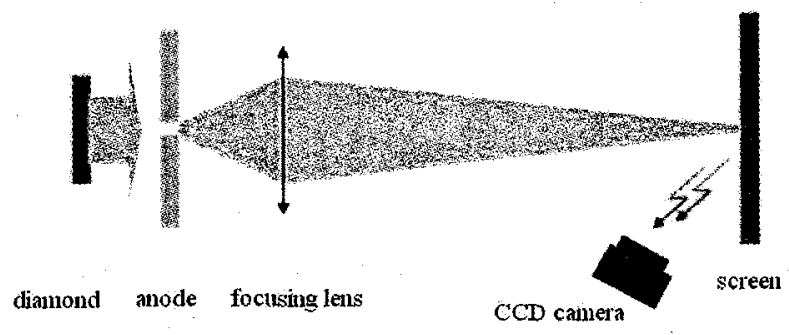

Figure 1: Setup design for thermal energy measurement of diamond secondary emission

\section{METHODS}

Common to all possible focusing schemes for thermal energy measurement is the application of a small aperture on the anode plate to limit the beam size, such that the beam size after a drift distance is measurable. In addition, the field applied for acceleration is constrained by the need to obtain a good gain in the diamond amplifier. The schematic layout of the cathode and anode is shown in Figure 2.

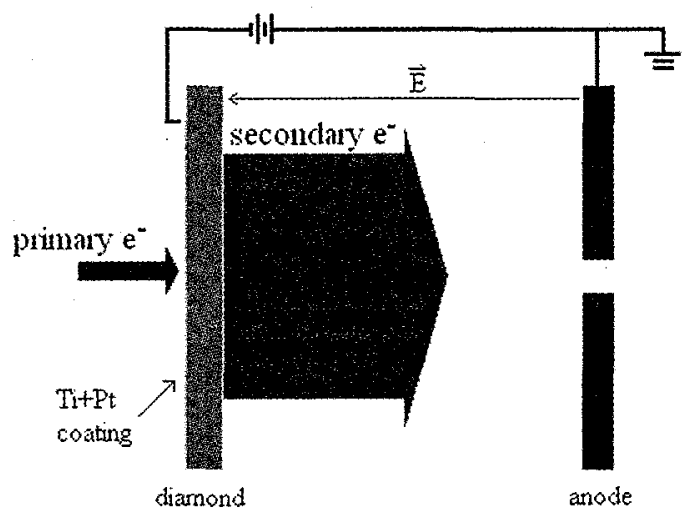

Figure 2: Acceleration of the secondary electrons by applying high voltage across

\section{LIMITATIONS}

The aperture in the anode applies a defocusing force on the electron beam, which is mainly a linear force with a small component of nonlinear aberration. A larger aperture will lead to a stronger aberration, and will cause increase in the beam spot size on the screen. Space charge is another issue in increasing the spot size. A small aperture in the anode also leads to a lower current with smaller space charge effect, increasing the accuracy of the measurement. On the other hand this will make the 
imaging more difficult. From simulation results in Figure 3 , we choose the upper limit for each effect.
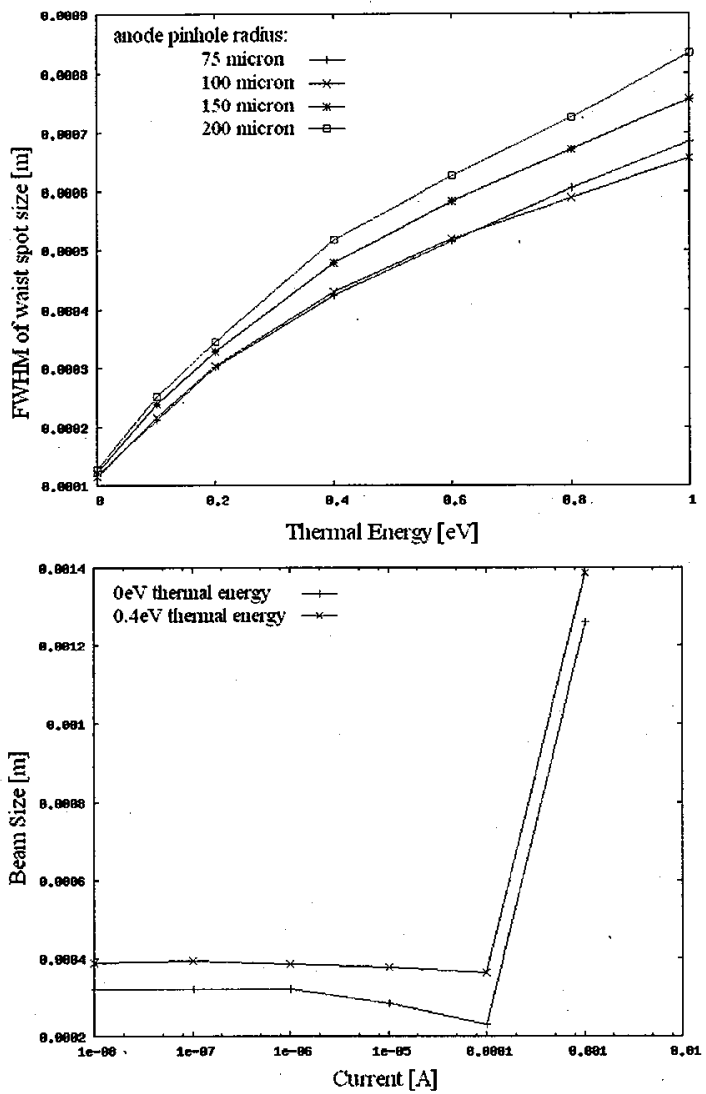

Figure 3: Aberration and space charge effects on beam spot size on screen.

The upper limit of the aperture and current is determined by leading to a small change in the spot size. From the simulation above, an aperture radius of $100 \mu \mathrm{m}$ and a current of $10 \mu \mathrm{A}$ are chosen.

\section{COMPARISON OF LENSES}

The criterion of choosing the focusing lens is the growth rate in beam waist spot size with respect to thermal energy of the cathode. A large growth rate as a function of temperature will minimize the system errors. Results from simulation of different kinds of focusing lenses are shown in Figure 4 and Figure 5. All curves in both plots are simulated with same distance from anode to lens $(2 \mathrm{~cm})$ and from lens to screen $(25.5 \mathrm{~cm})$ for comparison. In both plots, the solenoid has a faster growth rate compared to other lenses. In Figure $4,0.5 \mathrm{~cm}$ aperture Einzel lens growth rate is comparable with solenoid, but the nonlinear effect due to small aperture is significant, and this will result large system error for spot size measurement. The simulation also shows that the closer the lens is to the anode and the further is the screen location, the better is the resolution.

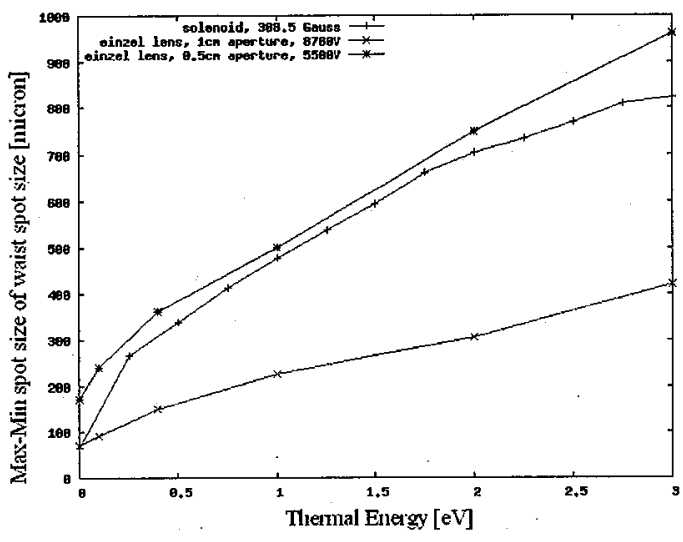

Figure 4: Comparison of solenoid and two Einzel lenses.

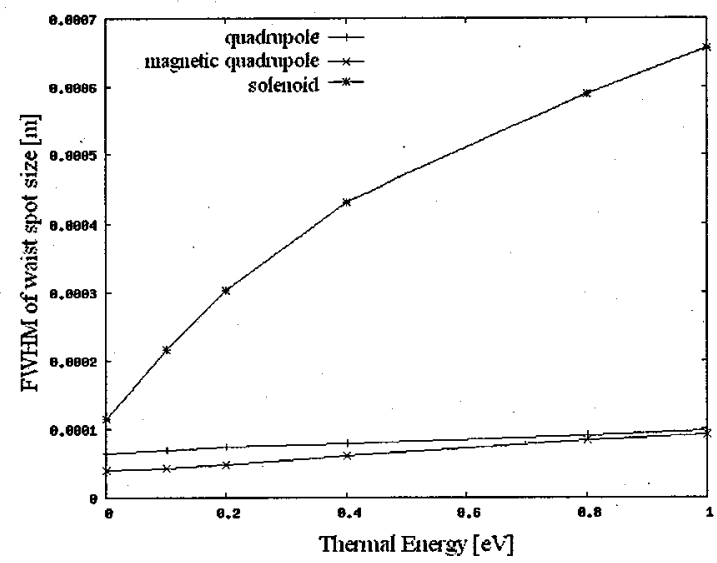

Figure 5: Comparison of solenoid and two quadrupoles.

Solenoid is the final choice of focusing lens.

\section{SHIELDING}

All components in the measurement setup have low permeability. Shielding the solenoid is very important to prevent a magnetic force on the electrons during acceleration, which will reduce the resolution. Figure 6 shows the performance of a solenoid with and without shielding, and compares with hard edge field.

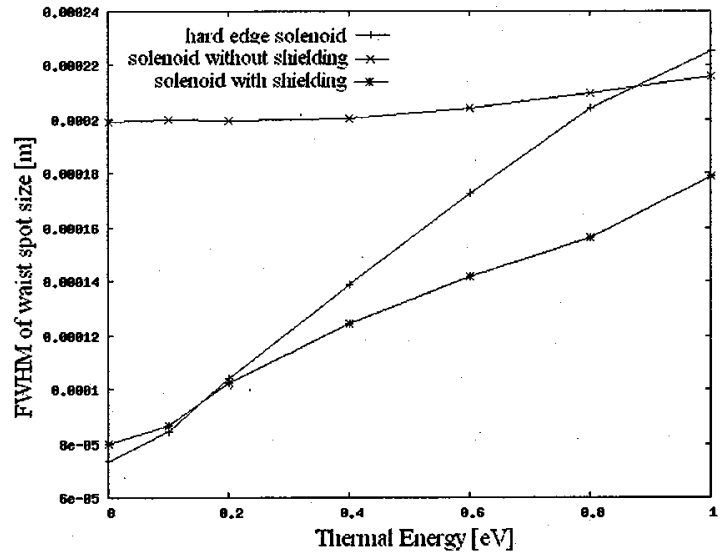

Figure 6: Solenoid with different shielding. 
Shielding material of $1 \mathrm{~mm}$ thick with relative permeability $\mu_{\mathrm{r}} \sim 20,000$ around the solenoid coil will decrease the magnetic field at the anode to $<1.5$ Gauss. Solenoid without shielding gives the worst resolution (green), while the resolution of solenoid with shielding of $\mu_{\mathrm{r}}=20,000$ (blue) is comparable with hard edge ideal case (red).

\section{ALIGNMENT}

The setup design is based on highly accurate alignment of the anode pinhole and the solenoid center axis. It is very important to have the secondary electron beam, after passing through the anode pinhole, symmetrically distributed around the solenoid center axis in transverse direction. This avoids the distortion of the waist spot on the screen.

During the alignment, a laser beam is passed through the system downstream of the electron path. Along the laser path, the anode pinhole and three additional $250 \mu \mathrm{m}$ diameter pinholes are used to conduct the alignment. Two are mounted on the center of the flanges at each end of the system. The third is located at the center of the start point of the solenoid field. With the laser beam passing all four pinholes, the offset of secondary electron beam away from the solenoid center axis is kept smaller than $150 \mu \mathrm{m}$.

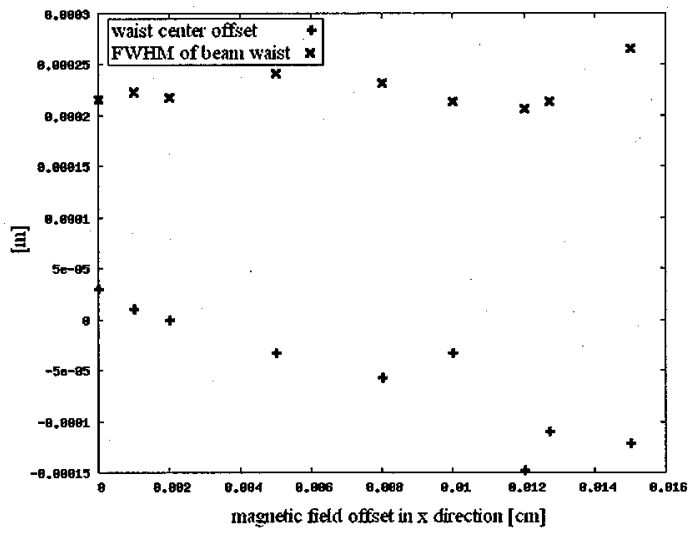

Figure 7: The offset magnetic field to the center of the electron beam and the waist FWHM difference according to the offset. Thermal energy of the beam is $0.1 \mathrm{eV}$.

This procedure also insures that the solenoid axis is perpendicular to the anode surface, and the tilt angle can be controlled to better than $5 \mathrm{mrad}$.
Figure 7 shows the simulation of the beam waist FWHM change due to different offset of the electron beam for $0.1 \mathrm{eV}$ thermal energy. Thus the error caused by offset after alignment should be a very small value. A quadrupole lens may be added to the drift section for additional correction so as to lower the error even more.

\section{CONCLUSION}

With the design of the solenoid lens based measurement system shown in Figure 1 and the calibrated simulation plot of FWHM waist spot size vs. thermal energy, a CCD camera with pixel size $\sim 5 \mu \mathrm{m}$ should be able to analyze the beam waist spot size down to $50 \mu \mathrm{m}$ diameter. Thus, we should be able to determine the thermal energy of diamond secondary emission to about $0.01 \mathrm{eV}$.

Careful alignment and shielding is very important in minimizing the systematic error.

The limit of thermal energy measurement from aberration of aperture of anode and space charge effect is $100 \mu \mathrm{m}$ in radius and $10 \mu \mathrm{A}$ for secondary electrons respectively.

By changing the focusing strength of lens, the waist of electron beam will be imaged on screen at a specific location. For good resolution, lens should be as close to the anode as possible, and the screen should be relatively far away from the lens.

\section{REFERENCES}

[1] X.Y. Chang, I. Ben-Zvi, A. Burrill, P.D.J. Johnson, J. Kewisch, T. Rao, Z. Segalov, Y. Zhao, Study of Secondary Emission Enhanced Photoinjector, Proceedings PAC05, Knoxville Tennessee, May 16202005.

[2] X.Y. Chang, I. Ben-Zvi, A. Burrill, S. Hulbert, P.D.J. Johnson, J. Kewisch, T. Rao, Z. Segalov, J. Smedley, Y. Zhao, Measurement of the Secondary Emission Yield of a Thin Diamond Window in Transmission Mode, Proceedings PAC05, Knoxville Tennessee, May 16-20 2005.

[3] X. Chang, I. Ben-Zvi, A. Burrill, J. Grimes, T. Rao, Z. Segalov, J. Smedley, Recent Progress on the Diamond Amplified Photo-cathode Experiment, Proceedings PAC07, Albuquerque, New Mexico, June 25-29 2007. 